\title{
Analyzing Social Policy from a Network Perspective
}

\author{
Jill Manit \\ Aleksey Kolpakov \\ William Eubank
}

\begin{abstract}
Governance models influence the approach that public service organizations take when implementing programs, policies, and practices. The networked model of governance supports the involvement of multiple actors who span organizational boundaries and roles to implement solutions to address complex social problems. This paper presents the utility of network analysis for the study of policy implementation from a network perspective. The paper describes networks within the context of social work policy implementation, basic network components, common structural variables, and sources of data for the study of policy implementation. A study of a statewide policy implementation is partially presented as an illustration of the use of network analysis in social policy research. The illustration uses primary and secondary data with network analysis techniques to identify and describe the patterns of interactions that comprise the structure of the implementation network. The illustration will present examples of the study findings to demonstrate the utility of network analysis in identifying central network actors and describing the density of the network according to different network variables. The paper concludes with a summary of the utility of network analysis in the study of policy implementation with recommendations for future research.
\end{abstract}

Keywords: Networked governance; network analysis; policy implementation; policy process

In responding to complex social problems, social work policy researchers and practitioners are frequently called upon to advocate for, develop, and implement policy solutions that are vague and span multiple entities. The type of governance model used to guide implementation influences incentives, opportunities, and constraints which become the context of the policy implementation. Attention to the implementation process is important for providing a contextual understanding of how social workers can both influence and explain policy outcomes. Emerging attention to the role of networks across the policy process requires social work policy researchers and practitioners to apply network analysis techniques to the study of policy implementation in social work.

The networked governance model has been gaining attention as it attends to both the complexity and the boundary spanning issues of policy implementation. Measuring the impact of this type of governance structure is as complex as the implementation itself. However, the rise of analytical tools and prolific publication of network analysis research has resulted in increased attention to analyzing policy implementation from a networked governance perspective. Monge and Contractor (2003) state "complex systems analysis explores the behavior of a network ... the network is important because it provides the context or the environment for the individual agents" (p. 86).

Jill Manit, Ph.D., MSW, Clinical Assistant Professor, Social Work Department, Fairfield, CT, 06825; Aleksey Kolpakov, Ph.D., Assistant Professor, Department of Political Science, University of Nevada Reno, Reno, NV, 89557, William

Eubank, Ph.D., Associate Professor, Department of Political Science, University of Nevada Reno, Reno, NV 89557 
In policy implementation, the network can be the dependent variable whereby the researcher is concerned with factors that impact the formation and operation of the network itself; or, it can be the independent variable whereby the structure of the network impacts the outcomes of implementation (Yang, Keller, \& Zheng, 2017). Additionally, network analysis can serve as a tool for social work policy practitioners to empirically analyze measures of power that are essential to informing strategies aimed at influencing policy. This paper presents network analysis as a methodological approach to the study and practice of policy implementation.

The fundamental premise is that the governance approach used during implementation influences the outcomes of the policy or program. More specifically, the patterns of interactions within a networked governance approach shapes the incentives, opportunities, and constraints of implementation which, in turn, impacts the outcomes. This paper describes the basic premises of governance, networks, network analysis and its varied application as both a tool and an analysis of policy implementation. Common network measures such as centrality and reciprocity are described for their utility in empirically analyzing critical aspects of policy practice including identifying decision-makers, an understanding of power, and maximizing the diffusion of information and resources.

A statewide policy implementation is partially presented as a case illustration of the use of network analysis in social work policy research. The illustration describes the use of primary and secondary data with network analysis techniques to identify and describe the patterns of relationships in a network. The illustration will present examples of the study findings to demonstrate network analysis' utility in identifying central network actors and describe the density of the network according to specific network variables. The paper concludes with a summary of the utility of network analysis to study the social policy with recommendations for future research.

\section{Governance and Policy Implementation}

\section{Governance}

Governance is not synonymous with government; it is focused on an overarching structure and meaning of government as opposed to the functions of government itself (Rhodes, 1996). Governance is more about the "process" of governing as opposed to the institutions themselves (Bevir, 2012, p. 11). In their summary of the literature on governance, Or and Aranda-Jan (2017) describe governance as encompassing a movement to pull back from state-based perspectives while adding increased involvement of citizens. While there are "imprecise" definitions of the term "governance" (Rhodes, 1996, p. 652), one definition is "the pursuit of collective interests, with the state as a coordinating and enabling actor" (Pierre, 2011, pp. 984-985) and "at its most basic level, governance means the capacity to steer the economy and society toward collective goals" (Peters, 2011, p. 996).

Governance is a process that is both internal to the state as well as external as it interacts with "other actors in society" (Pierre, 2011, p. 985). The increasing complexity of social problems requires the capacity of multiple governments and partners to solve problems 
through formal and informal network partnerships. The networked governance model has emerged as the set of institutions, their arrangements and relationships that impact how policies are developed and implemented (Pierre, 2011).

Network Governance Model. Older generations of bureaucracy aimed to solve problems that were more specific and discrete (Agranoff \& McGuire, 2001). In doing so, there was greater ease in developing and implementing policy instruments focused on insulated goals and objectives and implemented with hierarchical control. However, with increased attention to complex problems where solutions are either unknown or not feasible, there has been a shift in governance to a networked approach. This approach becomes one of "governance with government" (Weber \& Khademian, 2008, p. 341) whereby government retains an obligation to the public good while acknowledging government, alone, cannot solve problems. Rather, it can serve as a catalyst and facilitator of the networked model.

The network model of governance is responsive to "complex public problems" (Weber $\&$ Khademian, 2008, p. 335). In response to such complex problems, there is typically the formation of special task forces, committees, work groups, or public-private partnerships, who organize to coordinate a response (O'Toole, 1997). The response to such problems typically involves the implementation of complex policy solutions in partnership with multiple individuals and organizations across public and private sectors (Agranoff, 2017). "It is at the local level where policies and programs are implemented, where the routines build policy, and where the enduring challenges of promoting economies, eliminating poverty, integrating immigrants, and building democracy take place" (Agranoff, 2014, p. 57S). As such, the networked approach provides a structural mechanism for shared information, resources, and expertise across policy partners (Weber \& Khademian, 2008). There has been a rise in the networked governance approach since the global financial crisis of 2008 when resources for public services were constrained (Or \& Aranda-Jan, 2017). In response, flexible and collaborative service arrangements across public and private sectors became a strategy for maximizing limited resources.

A basic premise of the networked governance model is the state does not carry the sole burden of solving the problem and it involves actors who are close to the problem in developing the solution. This model includes a shift from the state being the sole provider of services to an increasing trend where the central government is providing funds to "regional actors" to implement policy solutions (Klaster, Wilderom, \& Muntslag, 2017, p. 676). The nature and structure of this coordination is referred to as a network. The characteristics of the network, such as the patterns of relationships amongst the actors, can impact the outcomes of the policy on the social problem. Hall and O'Toole (2000) describe the phenomenon of multiple organizations working together on all or parts of the program as "networked arrays" of implementation (p. 673). Networked implementation assumes "outcomes and performance result from interactions between a variety of actors rather than from the actions and policy of one actor alone" (Klign \& Koppenjan, 2012, p. 589).

Networked governance shifts policy implementation from the sole public entity responsible for the policy to a collaborative network consisting of actors from public and private entities who have a stake in the outcome of the policy. However, the network 
perspective does not necessarily replace the bureaucratic perspective (O'Toole, 2014). Instead, it adds layers of "structural complexity" (O'Toole, 2014, p. 361). The rise of networks in policy implementation is a result of trends in dispersing resources across public and private entities and shifts from a hierarchical approach to more collaborative decisionmaking processes amongst actors involved in the development and implementation of policy solutions (Knoke, 2011).

\section{Networked Implementation}

When viewed as a process, stakeholders or actors engage in public policy across phases ranging from problem identification and agenda-setting to implementation and evaluation (Birkland, 2001; Weible \& Sabatier, 2018). Implementation is a "problem-solving activity that involves behaviors that have both administrative and political content" and it unfolds as a process over time (Goggin, 1986, p. 330). Governance structures such as those described above impact the resources, constraints, and opportunities necessary to implement policies.

Implementation of public programs from the networked perspective essentially means "funding and implementation will not be concentrated in a single government entity" (Weber \& Khademian, 2008, p. 341). Within networked implementation "interorganizational linkages" become a central component of implementation whereby "governance is about managing networks" (Rhodes, 1996, p. 658). Under this model, a government entity may take on the role of creating and managing networks for problem solving and service delivery as opposed to directly providing services. By nature of complex problems, it is not always feasible to achieve policy or program outcomes in the exact manner initially prescribed. Thus, the benefit of networked implementation can be its responsiveness to programmatic needs and resources. However, networked implementation presents unique challenges for conducting research on the effectiveness of the network activities.

Dispersed service delivery under a networked implementation model presents a challenge as there is reduced control over the specific program activities. Private providers may be less inclined to abide by strict implementation rules; thus, making it difficult to achieve accountability and performance outcomes (Agranoff, 2017; Rhodes, 1996). Describing or predicting how a network's structure impacts outcomes becomes as complex as the implementation itself. Networked implementation is multi-level and involves multiple actors across various levels in a flexible and adaptable manner. It is not a stagnant nor prescriptive approach to implementation. Analyzing policy implementation from a networked perspective acknowledges the inherent complexity and impact of context. At the same time, it also acknowledges the difficulty in measuring implementation from this perspective (Ward, Stovel, \& Sacks, 2011).

\section{Networks}

A network is comprised of actors (individuals, groups, organizations) who use "flexible, dynamic communication linkages" to span boundaries and work collaboratively on complex issues (Contractor, Wasserman, \& Faust, 2006, p. 681). From those efforts, 
patterns of relationships amongst the actors emerge (Kapucu, Hu, \& Khosa, 2017). The patterns of relationships occur at different levels: the individual actor, between two actors (dyads) and relationships between small groups (Yang et al., 2017). The patterns of relationships across the different levels comprise the overall structure of the network (O'Toole, 1997; Ward et al., 2011; Wasserman \& Faust, 1994). Essentially, the network structure is the collection or pattern of smaller structures within the network. The network structure represents an interdependence amongst the actors where hierarchy is not simply the result of a formal position or bureaucratic structure (O'Toole, 1997).

One of the earliest known studies of a social network was by psychiatrist Moreno in 1933 (Ward et al., 2011; Yang et al., 2017). The New York Times (1933) reported his study of relationships amongst girls within a school. In his results he was able to identify girls who are isolated, cliques, as well as popular and unpopular girls. Moreno accurately predicted that two of the girls would run away from the school. Moreno was quoted as stating "such an invisible structure underlies society and has its influence in determining the conduct of society as a whole" (The New York Times, 1933, p. 17). In applying Moreno's statement to the study of policy implementation, the "invisible structure" would underlie the context of implementation thereby influencing the outcome of the policy.

Policy networks consist of "a set of public and private corporate actors linked by communication ties for exchanging information, expertise, trust and other political resources" (Kenis \& Schneider as cited in Knoke, 2011, p. 211). Given a network is comprised of individuals and organizations connected through various types of relationships, network analysis is the study of those patterns of relationships that comprise the structure of the whole network. While this notion of collaborative policy implementation is not new, the use of network analysis to empirically describe and predict network outcomes is on the rise.

\section{Application to Social Work Policy Research and Practice}

Network analysis and policy implementation have several applications to social work policy research and practice. When treated as the independent variable, the structure of a network can be used to explain and, to a certain extent, predict contextual factors of the implementation outcomes such as access to resources (Yang et al., 2017). When treated as a dependent variable, a social work practitioner can employ network analysis to understand specific network behaviors and factors that may influence those behaviors (Yang et al., 2017). For example, a social worker facilitating a networked response to a social issue may employ network analysis to understand the patterns of information dissemination and referral structures of community-based services. Or, they may utilize network analysis to understand and identify strategies for building certain relations such as trust amongst their network members.

Network analysis can also describe the patterns of connections amongst network subgroups (i.e., cliques). This information is useful to the social worker in identifying strategies to navigate sub-groups, facilitating sharing of key resources across network members and identifying communication breakdowns as a result of "structural holes" in the network (Burt, 1992, p. 27). For example, when implementing a needle exchange 
program, the social worker may discover that both the network of organizations as well as the recipients of the program operate in geographically organized cliques. The social worker can identify organizations or stakeholders that "span" the boundaries of the cliques and utilize them to improve coordination amongst all entities. Thus, the network itself is a form of social capital whereby it becomes the "conduit" for the flow of information and resources and is impacted by the size and range of the network (Burt, 1992, p. 12).

Additionally, network analysis can be used as a tool for analyzing power within the policy arena. For example, Lane and Pritzker (2018) describe strategies for assessing power within the political context. In their text, the authors describe specific tools for conducting a "power analysis" or creating a "power map" (pp. 97-99). Network analysis techniques can be employed to empirically analyze the results of such power analyses utilizing the tools Lane and Pritzker describe as sources of data.

\section{Basic Network Components}

The following describes the basic components of a network, which is necessary to define before describing network analysis as a methodology.

Nodes. The members of the network, who become the focus of the analysis are often referred to as the actors (Wasserman \& Faust, 1994). In the public policy field, they may also be considered key stakeholders. As stakeholders, network members can include funders, clients, and members of the general public (Klaster et al., 2017, p. 677). In network analysis, the actors are described as nodes (Lecy, Mergel, \& Schmitz, 2014; Mischen \& Jackson, 2008). In visual depictions of networks, nodes are typically represented by a circle or dot. However, colors, shapes, and sizes can also be assigned to the nodes to illustrate certain characteristics of those nodes.

Ties. Ties are the types of relations that connect nodes throughout the network (Yang et al., 2017). How a tie is defined is often dependent on the nature of the study. Common approaches in defining ties can include physical presence together such as working together in an organization, inclusion or proximity to a geographic area, interactions such as attending events at the same time (Lecy et al., 2014), and communication (Mischen \& Jackson, 2008). Ties can represent specific dimensions of interorganizational relations, including trust, support, and the exchange of resources (Knoke, 2011).

Bridges. When a network is visually depicted, it is possible to observe clusters of network members tied as groups or cliques. Given these clusters, there may be some network members connected to more than one group, i.e., span groups. These network members are referred to as the bridge. Granovetter (1973) describes the important role of bridge actors as they can serve as the only information route between other actors who would otherwise not be connected.

\section{Network Analysis}

Network analysis is the study of the patterns of connections among actors within a policy or administrative arena (Provan, Veazie, Staten, \& Teufel-Shone, 2005). Network analysis "provides a language and methodology to examine relationships in order to 
facilitate the achievement of goals, such as implementing policy, or to identify roadblocks to successful implementation" (Mischen \& Jackson, 2008, p. 324). An understanding of the network structure can provide insights into the potential successes, barriers, and changes necessary for a network to function effectively.

In any network analysis, it is important to define the boundaries of the network to be studied. However, it can be difficult to draw an absolute boundary as the network actors are "relatively bounded" (Wasserman \& Faust, 1994, p. 31). There are two kinds of network research designs: whole network and individual or ego network designs (Borgatti, Everett, \& Johnson, 2013; Marsden, 2011; Yang et al., 2017). The whole network approach studies the ties amongst all nodes within the network and is concerned with how those ties comprise an overall network structure (Marsden, 2011; Yang et al., 2017). The individual or ego network approach places the individual or node in the center of the analysis and is concerned with the ties connected to a particular node (Marsden, 2011; Yang et al., 2017). The whole network approach is most appropriate in the study of policy implementation. However, the individual or ego approach may be useful in analyzing power or specific patterns of interaction for targeted individuals such as elected officials.

There are two primary types of variables included in network analysis: structure and composition (Wasserman \& Faust, 1994). As discussed above, structural variables are the distinct transactions or ties between pairs of actors within the network; whereas, composition variables measure certain attributes of the actors such as basic demographics and geographic locations (Wasserman \& Faust, 1994). Thus, conducting a network analysis requires a determination of whether to measure only the structure or to also include an analysis of the composition of the structure.

\section{Sources of Data in Network Analysis}

Primary sources of data in network analysis typically ask respondents about their network relations directly via interview or survey. Surveys are one of the most common sources of data in network analysis (Kapucu et al., 2017). "Because social network data are relational, the survey instruments used to collect the data are formatted quite differently from traditional surveys" (Mischen \& Jackson, 2008, p. 324). The surveys typically include a list or roster of names of actors known to be in the network and then asks respondents specific questions about their relational ties to each of the actors. In an open-ended or free recall format, respondents may be prompted to generate their own list of actors and then respond to questions about their relational ties to the actors they named (Wasserman \& Faust, 1994). Common threats to the validity in the design and collection of primary network data include: omission errors, commission errors, node attribution errors, data collection and retrospective errors (Borgatti et al., 2013). In analyzing policy implementation, network actors may be surveyed on their patterns of interaction with other members of the network specific to the implementation activities such as sharing information and resources or referring clients to one another.

Secondary sources such as government records, newspaper articles, and online resources are common sources of data for identifying connections between actors such as attendance at events, similar behaviors such as voting or positions on social issues (Borgatti 
\& Halgin, 2011). Other secondary sources included in large network studies include patterns of interaction in social media platforms and online behaviors such as commenting or liking certain web pages.

\section{Common Measures in Network Analysis}

Given network analysis is the study of relationships among specified actors, those relationships are not independent from one another nor is the sample representative of the general population. Therefore, common statistical methods such as analysis of variance are not typically employed in network research (Borgatti et al., 2013; Contractor et al., 2006; Monge \& Contractor, 2003). There is a reliance on "graph realizations" to measure the patterns of relationships existing at multiple levels where the number of actors in a network are graphed with the number of possible ties with other members of the network (Contractor et al., 2006, p. 685). While not exhaustive, the following describes common statistical methods to analyze network structure at multiple levels of analyses (actor level, dyadic, and triadic).

Density. The density of a network is a whole network level measure of the total ties measured in relation to the total number of possible ties (Yang et al., 2017). Density describes the overall connectedness of the network actors (Milward, Provan, Fish, Isett, \& Huang, 2010; Provan et al., 2005; Yang et al., 2017). This produces an analysis of the network structure ranging from sparse, where there are not many ties between actors, to dense indicating a large number of ties (Contractor et al., 2006; Monge \& Contractor, 2003). High levels of density are not always indicators of network effectiveness as the increase in number of ties generally requires increased costs in managing those ties (Milward et al., 2010). Density may also influence an actor's decision to participate in the network. For example, if it takes too many resources (i.e., time) for the actor to gain access to information, then this sets the context for their participation behavior.

Centrality. Centrality is both an actor level and a whole network level measure (Yang et al., 2017). Within a network, central actors are influential in the flow of information, opportunities, constraints, and resources important to policy implementation. Crucial to this centrality are characteristics of trust, reputation, and influence (Provan, Huang, \& Milward, 2009). At the whole network level of analysis, overall centralization represents the distribution of ties amongst the actors in the network (Yang et al., 2017). In other words, a highly centralized network would be represented by a small number of people with the greatest number of ties. Network structures with a high degree of centralization are more likely to achieve their collective goals (Contractor et al., 2006).

In social work policy research and practice, centrality is one of the most useful empirical measures of power amongst network actors. At the actor level of measurement, centrality is the actor's unique position within the network and is an indication of power (Borgatti et al., 2013). Centrality is a measure of connectivity among the actors within the network (Borgatti \& Halgin, 2011; Contractor et al., 2006). Identification of actors who are more "central" in the network can indicate who has increased power through their access to others. Additionally, central actors can inhibit or promote the spread of knowledge and innovation (Mulvaney, Lee, Hook, \& Prokopy, 2015). Borgatti (2018) 
describes four common actor level measures of centrality: degree, betweenness, closeness, and eigenvector. The following describes the degree and betweenness centrality measures as they are common in network analysis (Yang et al., 2017).

The "degree measure of centrality" is the number of direct ties an actor has with other actors in the network and is an indication of power and prestige within the network (Borgatti \& Halgin, 2011; Contractor et al., 2006; Yang et al., 2017). In network communications, a large number of ties can increase communication and mutual trust (Mulvaney et al., 2015). When utilizing survey data, centrality is based on the respondents' perception of how central a node is within the network and is measured by the number of direct or indirect ties a network member has (Klaster et al., 2017; Provan et al., 2005).

The "betweenness centrality" measure captures the position of an actor as a bridge between others in the network, where they serve to connect network members who otherwise would not have been connected (Kolpakov, Agranoff, \& McGuire, 2016; Monge $\&$ Contractor, 2003; Mulvaney et al., 2015). Centrality is a measure of the frequency with which a given actor falls along the shortest path between other actors (Borgatti et al., 2013). The path is the ties between the network actors. A higher betweenness score indicates an actor is along the shortest path between the other nodes lending power to that actor as information, for example, would have to go through them in order to get to the others because they are "between" the actors.

Other network measures. Mutuality and reciprocity measure the extent to which actor's exchange information and resources and the extent to which the exchange is reciprocated (Contractor et al., 2006). The absence and presence of mutual and reciprocated ties can reveal clusters of relationships and expose patterns of the control or flow of information, opportunities, constraints, and resources. Additionally, the triadic level of measurement analyzes the structure of relationships amongst groups of three actors and the frequency those structures are present throughout the network. This level of analysis reveals the network's sub-structures and is an indication of the whole network structure such as the persistence of hierarchy in the network (Nooy, Mrvar, \& Batagelj, 2011).

\section{Case Illustration}

The networked governance perspective for public policy implementation is useful in describing how the network can shape resources, constraints, and opportunities associated with public policy implementation. The following provides an example of findings from a network analysis study on the implementation of a multi-agency and stakeholder effort to change a statewide service delivery system. The study examined the extent to which that effort resembles a network for implementation and describes the patterns of relationships that comprise the structure of that network. The study measured network structures across four relationship ties: working together, sharing information, sharing resources, and trust. A mixed method approach was employed by analyzing public meeting minutes as secondary data to first identify network actors and then implement a subsequent survey of those actors to analyze their patterns of interaction.

Table 1 presents the raw score of the overall density of the whole network across the four relationship ties. The closer a density score is to one, the higher the density of the 
network (indicating a high number of ties amongst the network actors). Thus, in the example below, the network is moderately dense for the "working together" relationship (.407) and sparse for the "trust" relationship (.201) meaning survey respondents reported fewer "trust" ties with other network actors when compared to the other relationships.

\section{Table 1. Overall Network Density by Relationship Variable}

\begin{tabular}{lcccc}
\hline & $\begin{array}{c}\text { Working } \\
\text { Together }\end{array}$ & Information & Resources & Trust \\
\hline & & & & \\
\hline Density & .407 & .262 & .229 & .201 \\
\# of Ties & 1039 & 668 & 583 & 512 \\
\hline
\end{tabular}

Figures 1 and 2 are visual representations of the same network density findings found in Table 1. Figure 1 is the network density for the "working together" relationship while Figure 2 represents density of the "trust" relationship. The decreased density is evident in the depictions by observing the decrease in the number of black lines (representing ties) from Figure 1 to Figure 2.

\section{Figure 1. “Working Together” Network Relationship}

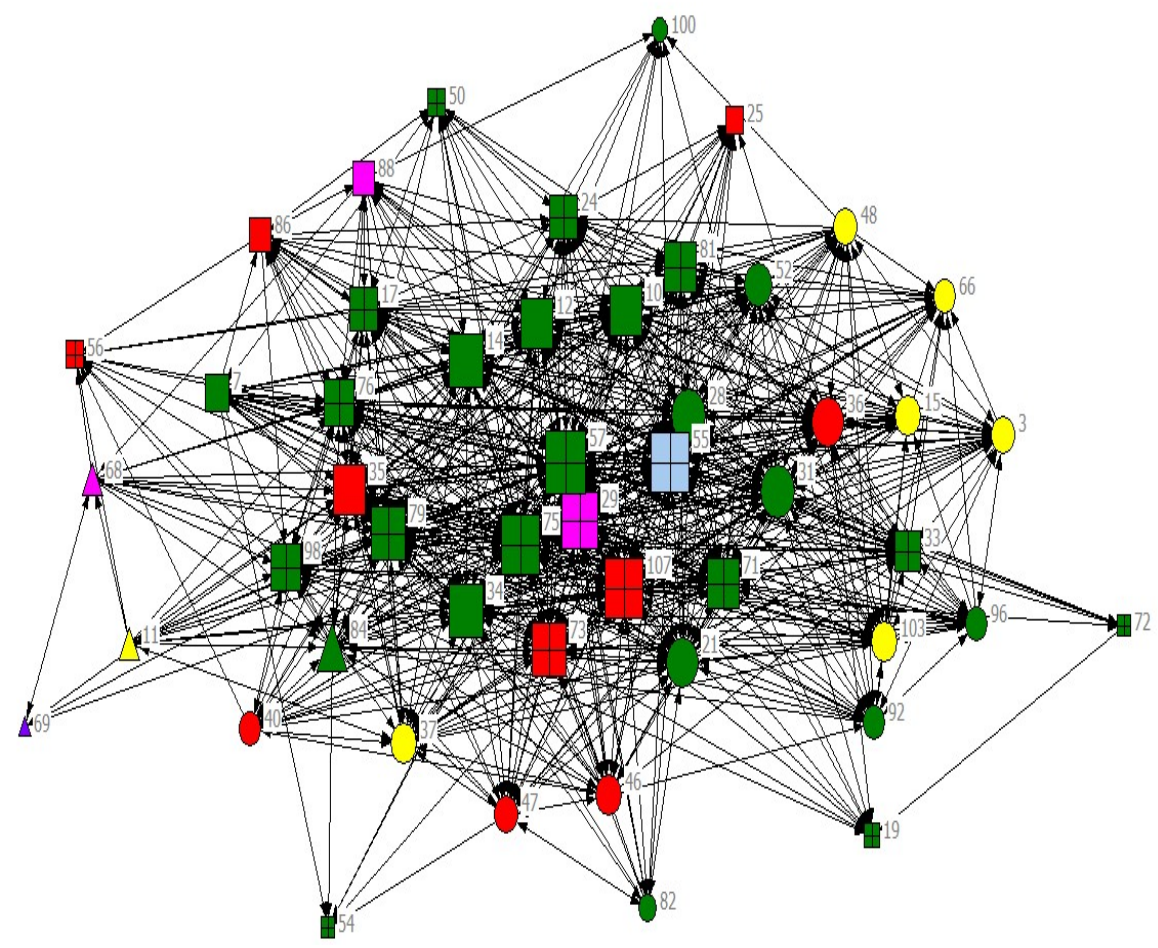

In Figure 1, the density is observed by the number of black lines (ties) amongst the nodes within the network. Utilizing a network analysis software program, the degree centrality technique measures how central an actor is within the network. In Figure 1, the actors' degree centrality is represented by the size of the shape representing the node; the 
bigger the shape, the more central the node. The varied shapes and colors included in the network visualizations represent the capacity to include attributes of an actor such as their job position or geographic location where each color or shape would represent a certain attribute. Thus, the social work researcher can utilize the network visualizations to identify actors that are most central, their attributes and observe their overall patterns of interaction. For example, the actors represented by circles in Figure 1 tend to have a smaller shape than those represented by a box, indicating decreased centrality for that role or type of actor. From an implementation standpoint, the central actor(s) have the "power" to control resources, constraints, and opportunities that impact implementation (Borgatti et al., 2013). From this understanding, social work policy practitioners can design strategies to influence policy by way of identifying and accessing the central actors in the network.

Figure 2. "Trust” Network Relationship

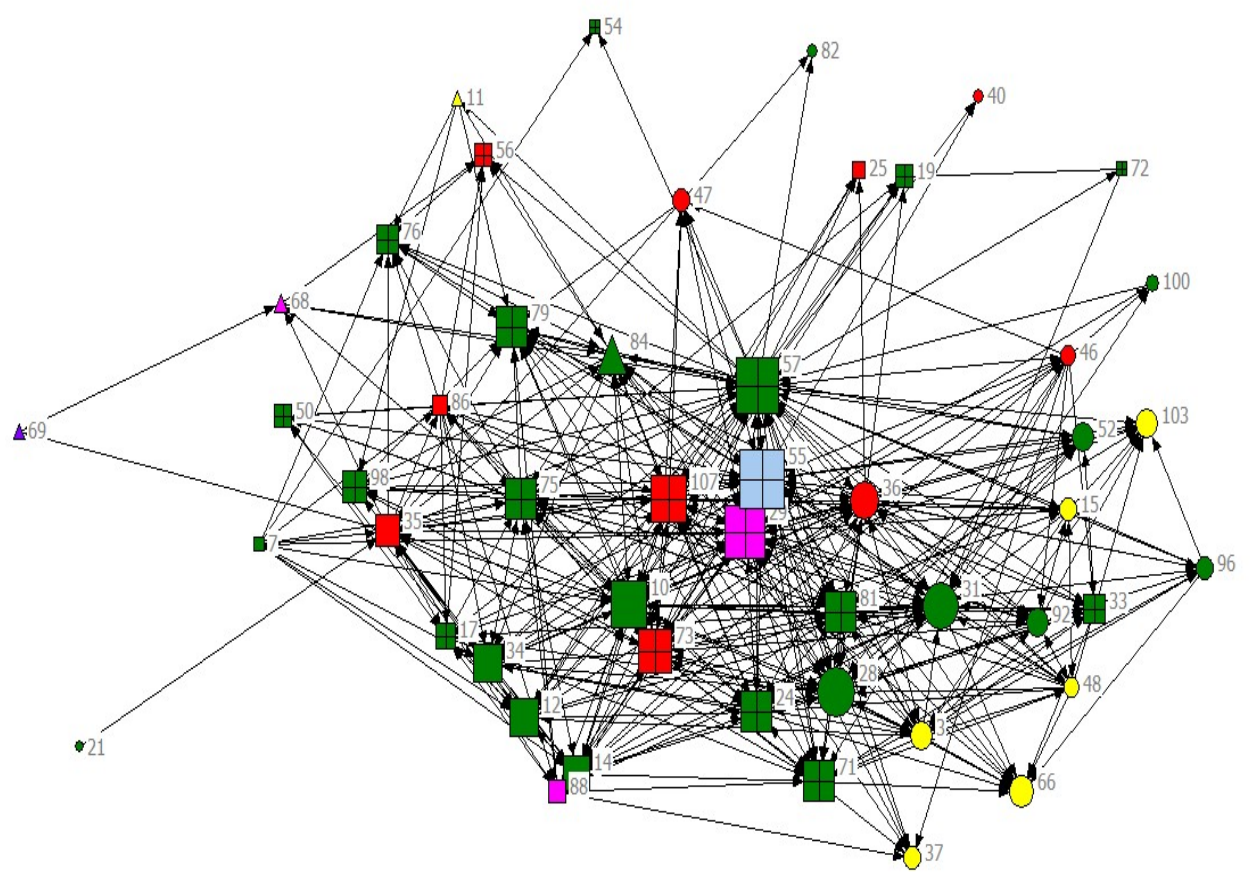

Figure 2 depicts the network for actors who share a "trust" tie. As depicted, there is a decrease in the number of black lines (ties) when compared to Figure 1. Essentially, actors within the network have more ties amongst one another for the "working together" relationships as opposed to those who reported having a trusting relationship with other actors in the network. While it may be obvious that it is easier to work together than to trust one another, the findings and visual depictions allow social work administrators to identify strategies necessary to successfully implement a policy. For example, an administrator can strategically position the central actors for trust (represented by the size of their shape) in key collaborative arrangements necessary for the implementation of the policy. 
In the depictions above, the central nodes are evident by the size of the shape associated with them. This is also supported in the individual level results reported in Table 2. Table 2 is an example of how network analysis can identify the most central actors within the network. The example lists the degree and betweenness centrality scores in rank order for the top five actors in the "trust" relationship. In their structural role, the central node(s) can control the flow of information (i.e., messaging), impede the travel of information (i.e., bottlenecking information), or promote expedited travel of information.

Table 2. Top Five Actors for Degree Centrality and Betweenness Centrality Scores, Trust Relationship

\begin{tabular}{|c|c|c|c|c|c|}
\hline \multicolumn{2}{|c|}{ Trust in Degree Centrality } & \multicolumn{3}{c|}{ Trust Betweenness Centrality } \\
\hline Rank & Actor \# & \# of Ties & Rank & Actor \# & \# of Ties \\
\hline 1 & 55 & 26 & 1 & 57 & 1081 \\
2 & 57 & 24 & 2 & 55 & 490 \\
3 & 29 & 23 & 3 & 84 & 311 \\
4 & 28 & 21 & 4 & 107 & 242 \\
5 & 10 & 20 & 5 & 29 & 220 \\
\hline
\end{tabular}

Again, social work policy researchers and practitioners can utilize network analysis in policy implementation by identifying strategies to strengthen a network, understanding the impact a network structure may have on policy outcomes, or as a tool for understanding power amongst actors within the network. For example, in Table 2, we can see that actors 55, 57 and 29 rank in the top five for degree and betweenness centrality for the trust relationship. Thus, power and influence over opportunities and constraints of implementation is centralized to a few actors within the public system. Strategically, a social work policy practitioner would devise ways to utilize the trust those actors have within the network to promote the goals of the network.

\section{Conclusion}

This paper is based on the premise that the type of governance structure a public entity employs influences how the policy or program is implemented, which then influences the outcomes achieved. The concept of networked governance provides a foundation from which to explain policy implementation from a networked perspective. The case illustration included is an example of how network analysis empirically describes the patterns of interactions amongst network members to inform the context of the policy or program implementation.

Embracing the networked approach in governance and policy implementation carries potential for the social work practitioner or lead implementing agency to draw upon the rich network management literature to strengthen the overall functioning of the network toward achievement of the goals. By doing so, the implementing agency acknowledges the power and influence that the network structure, as well as the individual actors within it, have to shape the opportunities and constraints of implementation. In turn, this increases our understanding of the process of implementation and evaluation of how the process impacts targeted outcomes. 
For example, key decision-makers frequently make sweeping conclusions about the success or failure of policies important to social work practice. Such dichotomous declarations are detrimental to policy implementation as the policy itself may have had sound goals, but implementation essentials such as information and resources are constrained by powerful opponents and prevent the policy from actualizing its potential. For example, a state legislative body may pass legislation to develop statewide violence prevention programs in schools. However, when the programs move forward to implementation, opponents who also occupy a central role in the implementing network (such as a school administrator), are in a position to constrain access to adequate resources for the program such as access to additional staffing. Thus, the violence prevention programs may appear ineffective for reasons that are unrelated to the specific program activities. In this example, a network analysis contextualizes such outcomes by identifying those who are central to the network and may or may not contribute to effective implementation. Network analysis would also identify the connections amongst the network members so that strategies to influence key decision-makers can be formulated. The social worker can then determine other in-network connections with access to the targeted actor. Equipped with their skill sets in engagement, communication, flexibility and facilitation social workers have the unique capacity to apply their skills to an understanding of network behaviors in order to organize and steer the network toward its goals.

The example above represents a distinction between policy implementation processes and policy outcomes (Goggin, 1986). As such, further study is needed to examine the extent to which a network's structure predicts network outcomes. Considering the example above, is a violence prevention program more likely to be effective if it is implemented by a dense, centralized and hierarchical network of actors? Or, is it more likely to achieve outcomes with a sparse and de-centralized network structure? Additionally, actors that are more central to the network have the power to influence incentives, create opportunities, or enforce constraints on others in the network. Who are those actors and to what extent did their power impact outcomes? Social workers have long embraced the notion that context impacts outcomes. Network analysis affords an opportunity to empirically describe this context as we evaluate programs and analyze policies.

\section{References}

Agranoff, R. (2014). Local governments in multilevel systems" Emergent public administration challenges. American Review of Public Administration, 44(4S), 48S62S. doi: https://doi.org/10.1177/0275074013497629

Agranoff, R. (2017). Crossing boundaries for intergovernmental management. Washington, D.C.: Georgetown University Press.

Agranoff, R., \& McGuire, M. (2001). After the network is formed: Process, power, and performance. In M. Mandell (Ed.), Getting results through collaboration: Networks and network structures for public policy and management (pp. 11-29). Westport, CT: Quorum Books. 
Bevir, M. (2012). Governance: A very short introduction. Oxford, UK: Oxford University Press. doi: https://doi.org/10.1093/actrade/9780199606412.001.0001

Birkland, T. (2001). An introduction to the policy process: Theories, concepts, and models of public policy making. Armonk, NY: M. E. Sharpe, Inc.

Borgatti, S. P. (2018, February 24). mgt 780 centrality 1 [video file]. Retrieved from https:/www.youtube.com/watch?v=FKM0f9QzlhU

Borgatti, S. P., Everett, M. G., \& Johnson, J. (2013). Analyzing social networks. Los Angeles, CA: Sage.

Borgatti, S. P., \& Halgin, D. (2011). Analyzing affiliation networks. In J. Scott \& P. Carrington (Eds.), The SAGE handbook of social network analysis (pp. 417-433). Los Angeles, CA: Sage.

Burt, R. (1992). Structural holes: The social structure of competition. Cambridge, MA: Harvard University Press.

Contractor, N., Wasserman, S., \& Faust, K. (2006). Testing multitheoretical, multilevel hypotheses about organizational networks: An analytical framework and empirical example. Academy of Management Review, 31(3), 681-701. doi: https://doi.org/10.5465/amr.2006.21318925

Goggin, M. (1986). The "too few cases/too many variables" problem in implementation research. The Western Political Quarterly, 39(2), 328-347. doi: https://doi.org/10.2307/448302

Granovetter, M. (1973). The strength of weak ties. American Journal of Sociology, 78(6), 1360-1380. doi: https://doi.org/10.1086/225469

Hall, T., \& O'Toole, L. (2000). Structures for policy implementation: An analysis of national legislation, 1965-1966 and 1993-1994. Administration \& Society, 31(6), 667-686. doi: https://doi.org/10.1177/00953990022019281

Kapucu, N., Hu, Q., \& Khosa, S. (2017). The state of network research in public administration. Administration \& Society, 49(8), 1087-1120. doi: https://doi.org/10.1177/0095399714555752

Klaster, E., Wilderom, C., \& Muntslag, D. (2017). Balancing relations and results in regional networks of public-policy implementation. Journal of Public Administration Research and Theory: J-PART, 27(4), 676-691. doi: https://doi.org/10.1093/jopart/mux015

Klign, E., \& Koppenjan, J. (2012). Governance network theory: Past, present and future. Policy \& Politics, 40(4), 587-606. doi: https://doi.org/10.1332/030557312X655431

Knoke, D. (2011). Policy networks. In Scott, J., \& Carrington, P. (Eds.), The SAGE handbook of social network analysis (p. 210-222). Los Angeles, CA: Sage. 
Kolpakov, A., Agranoff, R., \& McGuire, M. (2016). Understanding interoperability in collaborative network management: The case of Metro High School. Journal of Health Science, 4, 318-332.

Lane, S., \& Pritzker, S. (2018). Political social work: Using power to create social change. Cham, Switzerland: Springer International Publishing AG. doi: https://doi.org/10.1007/978-3-319-68588-5

Lecy, J., Mergel, I., \& Schmitz, H. (2014). Networks in public administration. Public Management Review, 16(5), 643-665. doi: https://doi.org/10.1080/14719037.2012.743577

Marsden, P. (2011). Survey methods for network data. In J. Scott \& P. Carrington (Eds.), The SAGE handbook of social network analysis (pp. 340-369). Los Angeles, CA: Sage.

Milward, H., Provan, K., Fish, A., Isett, K., \& Huang, K. (2010). Governance and collaboration: An evolutionary study of two mental health networks. Journal of Public Administration Research and Theory: J-PART, 20(supp. 1), i125-i141. doi: https://doi.org/10.1093/jopart/mup038

Mischen, P., \& Jackson, S. (2008). Connecting the dots: Applying complexity theory, knowledge management and social network analysis to policy implementation. Public Administration Quarterly, 32(3), 314-338.

Monge, P. R., \& Contractor, N. S. (2003). Theories of communication networks. New York, NY: Oxford University Press.

Mulvaney, K. K., Lee, S., Hook, T. O., \& Prokopy, L. S. (2015). Casting a net to better understand fisheries management: An affiliation network analysis of the Great Lakes Fishery Commission. Marine Policy, 57, 120-131. doi: https://doi.org/10.1016/j.marpol.2015.03.008

Nooy, W., Mrvar, A., \& Batagelj, V. (2011). Exploratory social network analysis with Pajek. New York, NY: Cambridge University Press. doi: https://doi.org/10.1017/CBO9780511996368

Or, N., \& Aranda-Jan, A. (2017). The dynamic role of state and nonstate actors: Governance after global financial crisis. Policy Studies Journal, 45(S1), S67-S81. doi: https://doi.org/10.1111/psj.12201

O'Toole, L. (1997). Treating networks seriously: Practical and research-based agendas in public administration. Public Administration Review, 57(1), 45-52. doi: https://doi.org/10.2307/976691

O'Toole, L. (2014). Networks and networking: The public administrative agendas. Public Administration Review, 75(3), 361-371. doi: https://doi.org/10.1111/puar.12281

Peters, G. (2011). Governance, Administration, Policies. In D. Berg-Schlosser, B. Badie, \& L. Morlino (Eds.), International encyclopedia of political science, Volume 1-8. Los 
Angeles, CA: Sage [EBook, EBSCO Publishing. Retrieved via University of Nevada Reno]. doi: https://doi.org/10.4135/9781412959636.n231

Pierre, J. (2011). Governance. In D. Berg-Schlosser, B. Badie, \& L. Morlino (Eds.), International encyclopedia of political science, Volume 1-8. Los Angeles, CA: Sage. doi: https://doi.org/10.4135/9781412959636.n230

Provan, K., Huang, K., \& Milward, B. (2009). The evolution of structural embeddedness and organizational social outcomes in a centrally governed health and human services network. Journal of Public Administration Research and Theory: J-PART, 19(4), 873-893. doi: https://doi.org/10.1093/jopart/mun036

Provan, K., Veazie, M., Staten, L., \& Teufel-Shone, N. (2005). The use of network analysis to strengthen community partnerships. Public Administration Review, 65(5), 603-613. doi: https://doi.org/10.1111/j.1540-6210.2005.00487.x

Rhodes, R. A. W. (1996). The new governance: Governing without government. Policy Studies, XLIV, 652-667. doi: https://doi.org/10.1111/j.1467-9248.1996.tb01747.x

The New York Times. (1933, April 3). Emotions mapped by new geography. Retrieved January 2, 2018, from https://www.nytimes.com/1933/04/03/archives/emotionsmapped-by-new-geography-charts-seek-to-portray-the.html

Ward, M., Stovel, K., \& Sacks, A. (2011). Network analysis and political science. Annual Review of Political Science, 14, 245-264. doi: https://doi.org/10.1146/annurev.polisci.12.040907.115949

Wasserman, S., \& Faust, K. (1994). Social network analysis: Methods and applications. Cambridge, NY: Cambridge University Press. doi: https://doi.org/10.1017/CBO9780511815478

Weber, E., \& Khademian, A. (2008). Wicked problems, knowledge challenges, and collaborative capacity builders in network settings. Public Administration Review, 68(2), 334-349. doi: https://doi.org/10.1111/j.1540-6210.2007.00866.x

Weible, C., \& Sabatier, P. (Eds.). (2018). Theories of the policy process (4th ed.). New York, NY: Routledge. doi: https://doi.org/10.4324/9780429494284

Yang, S., Keller, F., \& Zheng, L. (2017). Social network analysis: Methods and examples. Thousand Oaks, CA: Sage.

Author note: Address correspondence to Jill Manit, Ph.D., Social Work Department, Sacred Heart University, 5151 Park Avenue, Fairfield, CT, 06825.

manitj@sacredheart.edu 